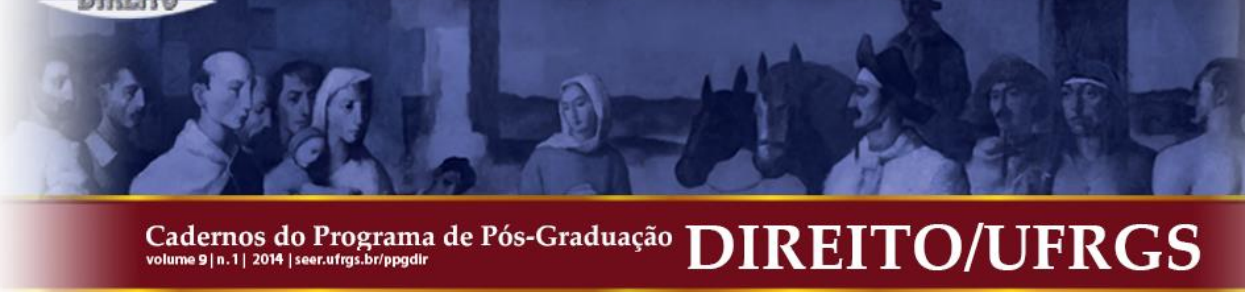

\title{
AS CONDIÇÕES PARA UMA PAZ DURADOURA. UMA LEITURA DE "A PAZ PELO DIREITO", DE HANS KELSEN
}

\author{
Arnaldo Bastos Santos Neto* \\ Ricardo Martins Spindola Diniz ${ }^{* *}$
}

\begin{abstract}
RESUMO: O pensador central da Escola Vienense de Direito, Hans Kelsen, dedicou-se ao exame de questões fundamentais do Direito Internacional, especialmente, após a eclosão da Segunda Guerra Mundial. Entre os seus textos mais interessantes da nova fase internacionalista, destaca-se "A paz pelo Direito", cujas teses mais importantes, como a defesa de um Tribunal Penal Internacional, a punição dos criminosos de guerra tanto dos lados vencidos como dos vencedores e ainda o papel propugnado por ele para os princípios do Direito Internacional, analisamos no presente artigo.
\end{abstract}

PALAVRAS-CHAVE: Tribunal Penal Internacional; Crimes de Guerra; Teoria Pura do Direito.
ABSTRACT: The central thinker of the Viennese School of Law, Hans Kelsen, devoted himself to the examination of the fundamental questions of International Law, especially after the break of the Second World War. Among his most interesting texts of this new internationalist phase, "Peace through Law" stands out, whose most important thesis, such as the defense of an International Criminal Court, the punishment of war criminals both for losers and winners, and also the role advocated by him to the principles of International Law, are analyzed in this article.

KEYWORDS: International Criminal Court; War Crimes; Pure Theory of Law.

SUMÁRIO: Introdução 1. O pacifismo jurídico kelseniano. 2. Além da soberania dos estados nacionais. 3. Por um tribunal penal internacional. 4. A questão da soberania. 5. O papel dos princípios. Considerações finais. Referências.

\section{INTRODUÇÃO}

No filme Julgamento em Nuremberg (Stanley Kramer, 1961), o roteirista Abby Mann inseriu um personagem - conforme o senso comum das faculdades de direito no Brasil - com ideias inspiradas na obra do jusfilósofo austríaco Hans Kelsen. O personagem Friedrich Hoffstetter, interpretado pelo ator Martin Brandt, faz a caricatura de um jurista legalista, aquele para quem a lei deve ser sempre obedecida não importa em que circunstâncias, exatamente o tipo de jurista contra quem Gustav Radbruch revoltou-se ao final da Segunda Guerra Mundial e responsabilizou como cúmplice por todos os crimes praticados pelo nazismo. Para um positivista, acusou Radbruch, "A lei é a lei", e, portanto, deveria ser cumprida em qualquer circunstância. Em sua declaração final ao tribunal, enquanto réu, Hoffstetter afirma: "Servi o meu país durante toda a minha vida. Em qualquer cargo para o qual fui designado servi com lealdade, pureza e sem maldade. Segui ao conceito que acreditava ser o mais importante em minha profissão. O conceito que diz: 'Sacrificar o próprio sentido de Justiça à ordem

\footnotetext{
* Universidade Federal de Goiás.

${ }^{* *}$ Universidade Federal de Goiás.
} 


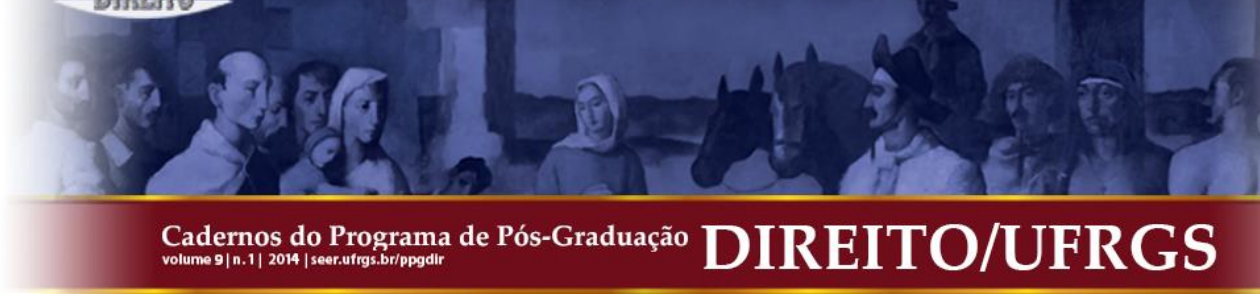

legal estabelecida. Perguntar apenas o que é legal e não perguntar o que é e o que não é justo'. Como juiz não podia fazer outra coisa. Acredito que os senhores encontrarão milhões de alemães como eu que acreditavam cumprir seu dever para com o seu país sem sentirem-se culpados".

A inspiração do malfadado personagem, todavia, não poderia ser mais equivocada, como faz prova o livro A paz pelo direito, publicado entre nós pela editora Martins Fontes, com uma precisa tradução de Lenita Ananias do Nascimento ${ }^{1}$. O livro foi originalmente publicado em inglês, em 1944, pela editora da Universidade da Carolina do Norte e traz algumas surpresas para os leitores que, porventura, acreditem que, na obra de Kelsen, exista qualquer tipo de atitude subserviente perante os textos legais ou aquilo que comumente chamamos de "legalismo" ou ainda conforme o que Norberto Bobbio chamou de "positivismo-ideológico".

O jurista vienense, por conta de seus escritos, chegou a ser chamado a Washington, em 1945, para atuar como assessor técnico da War Crimes Commission, tendo se ocupado por três meses dos preparativos técnico-jurídicos dos processos que iriam ser julgados em Nuremberg. Todavia, apesar de tal contribuição, Kelsen não participará pessoalmente dos julgamentos. Tampouco será chamado para participar, em São Francisco, da conferência de elaboração da Carta das Nações Unidas. Segundo seu discípulo e biógrafo Rudolf Métall, a única explicação para isto reside no fato de que "el jefe de la delegácion americana encargada del proyecto de la carta, Leo Pasvolsky. Habia contestado ya a las sugestiones que le habí a hecho Kelsen en Washington sobre el particular, diciendo que él, Pasvolsky, no concedia mucho valor a las "legalistictechnicalities!"2 Mesmo assim, vários membros de diversas delegações recorreram a Kelsen de forma não-oficial, entre eles, Roland Lebeau, da Bélgica, Eelco N. van Kleffens, da Holanda, e Vladimir Vochoc, da Tchecoslováquia.

No livro, o realista Kelsen, já definitivamente radicado nos Estados Unidos, perguntase pelas condições de uma ordem internacional garantidora da paz.O texto, com uma grande inspiração no Kant de A Paz Perpétua, é dividido em duas partes. Na primeira, Kelsen faz a defesa de uma liga permanente para a manutenção da paz, fundada sobre a igualdade soberana dos Estados, capaz de criar uma jurisdição internacional compulsória para dirimir as disputas entre os Estados. Na segunda parte, Kelsen ressalta a importância da responsabilização individual por violações ao Direito Internacional como garantia da paz. Após ter publicado textos fundamentais sobre a teoria do direito, que lhe granjearam uma enorme importância na

\footnotetext{
${ }^{1}$ KELSEN, Hans. A paz pelo direito. São Paulo: Martins Fontes, 2011.

${ }^{2}$ MÉTALL, Rudolf Aladár. Hans Kelsen, vida y obra. México: Unam, 1976, p. 85.
} 


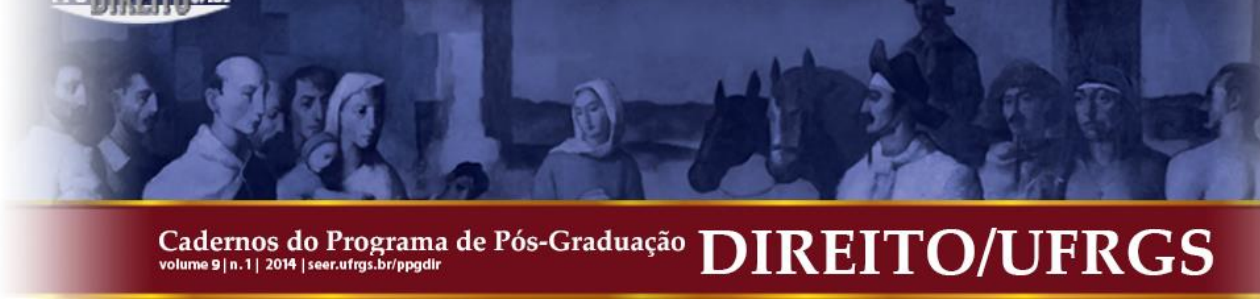

comunidade científica, nesta nova etapa de vida, Kelsen irá dedicar-se ao direito internacional, seguindo um modelo de forte inspiração kantiana, cuja marca será o monismo internacionalista, que assume a prevalência do direito internacional sobre o direito nacional.

\section{O PACIFISMO JURÍDICO KELSENIANO}

Para o espanto de quem acredita que Kelsen manteve qualquer tipo de atitude ambígua com relação aos crimes de guerra, o mestre de Viena defende não somente a punição dos mesmos como também que a perseguição criminal seja dirigida contra infratores de qualquer uma das potências envolvidas, incluindo vencedores e perdedores. Defende ainda que a lei utilizada para punir os crimes de guerra pode ser retroativa, alcançando situações não previstas na lei nacional ao tempo dos fatos. Algo muito distante da aceitação do argumento da "obediência devida" esgrimido pela defesa dos réus de Nuremberg.

Surpreende, no livro, também, um claro desvio com relação à postura epistemológica que Kelsen estabeleceu em seu texto cardeal conhecido como a Teoria Pura do Direito. Nessa conhecida obra, Kelsen advoga a ideia de uma epistemologia depurada de preconceitos advindos de outras áreas do conhecimento, como a política, a economia, a sociologia, a psicologia etc. O método proposto por Kelsen para a delimitação de uma ciência jurídica em sentido estrito é construído em conformidade com o objeto a ser analisado. A proposta kelseniana ficará conhecida também com o nome de "normativismo".

Para o pensador austríaco, a epistemologia jurídica deveria calcar-se no princípio da imputação, buscando um vínculo entre as normas e sua forma de estruturação hierárquica. Desvendadas essas conexões, o ordenamento jurídico pode ser apreendido simultaneamente em duas dimensões: uma estática e a outra dinâmica. A estática informando-nos o que dizem e como se relacionam as normas de um determinado ordenamento e a dinâmica informandonos sobre como esse mesmo ordenamento reproduz-se pela criação contínua de novas normas. O método proposto deveria focar na normatividade como condição para a construção de uma ciência jurídica digna desse nome, sem negar, no entanto, que, em outros momentos, o estudioso do direito não possa também efetuar investigações sociológicas, políticas, econômicas, psicológicas etc., com o uso das metodologias próprias de cada uma dessas ciências acerca do objeto jurídico. Há muito da visão weberiana e seus postulados metodológicos nessa proposta de Kelsen. 
revisión de la noción de soberania de los Estados, que dejara espacio a la construcción de instituciones 'supranacionales' y no simplemente interestatales"4.

\section{POR UM TRIBUNAL PENAL INTERNACIONAL}

Constatando a impossibilidade ou a inconveniência de um parlamento ou de um executivo universais, Kelsen, no entanto, fará uma defesa da instituição de uma jurisdição obrigatória, de um autêntico Tribunal Penal de Justiça Internacional. Inevitavelmente, a criação de um tribunal de justiça internacional que possa garantir as condições da paz possui, inegavelmente, um fundo moral e até mesmo uma opção política. Nesses momentos, Kelsen revela também suas dívidas para com Kant, para quem a paz aparece como uma das finalidades da História, exatamente quando a humanidade evolui na direção do particular para o universal. Para Kelsen, a guerra quando normatizada pode ser reduzida a uma sanção legítima do sistema de Direito Internacional.

Da defesa da criação de um tribunal compulsório, Kelsen passa, como de costume em sua obra, a analisar e refutar pontos da dita "doutrina tradicional" que se posicionariam contrários à sua proposta. $\mathrm{O}$ discurso kelseniano fundamenta-se em dois argumentos centrais. O primeiro argumento vem em resposta à seguinte pergunta: o que veio primeiro, a legislação ou os tribunais ${ }^{5}$ ? Enquanto o segundo: quais conflitos são jurídicos? Ou, melhor dizendo, existem conflitos não-jurídicos? Qual o limite entre, por exemplo, um conflito jurídico e um conflito político ${ }^{6}$ ?

À primeira, Kelsen responde em favor do segundo. É antropologicamente verificável, diz o autor, que muito antes de se ter algo próximo de um código escrito ou ainda de uma Assembleia ou Conselho responsável por tal, recorria-se a tribunais, ou a seus equivalentes, como modo de resolução de conflitos. Essa resposta encontra sustentação em aspecto peculiar, e muitas vezes negligenciado de sua obra, qualseja, o caráter criativo do direito. Só é possível afirmar, ou melhor, compreender, o dado factual - que é a precedência de tribunais, enquanto órgãos de decisão para a resolução de conflitos, a qualquer legislação ou órgão competente para criá-la - que se apresenta quando se aceita o aspecto criativo do direito. Nesse mesmo livro, mas em consonância com sua obra mais conhecida, a Teoria Pura do

\footnotetext{
${ }^{4}$ ZOLO, Danilo. La justicia de los vencedores. Madri: Trotta, 2007, p. 26.

${ }^{5}$ KELSEN, Hans. A paz pelo Direito. São Paulo: Martins Fontes, 2011, p. 20-21.

${ }^{6}$ KELSEN, Hans. A paz pelo Direito, p. 22.
} 


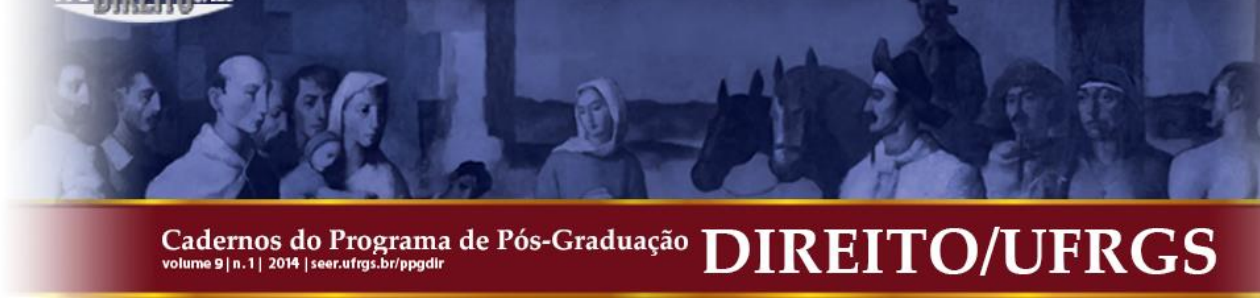

Direito, Kelsen afirma que toda aplicação do Direito implica na sua criação ${ }^{7}$. E, portanto, quaisquer razões contrárias à existência de um tribunal internacional que se baseiem na impossibilidade ou na necessidade de antes se criar um "Congresso Internacional" não tem, realmente, sua razão de ser.

Quanto à segunda, Kelsen entende que não existam "conflitos não-jurídicos" desde que não se queira que assim o sejam. O pensamento ao qual se dirige a crítica de Hans Kelsen é aquele que diz que um tribunal internacional compulsório que tentasse regular e tratar da guerra como modo de sanção, estaria indo além de suas capacidades, por se tratar de conflito eminentemente político ${ }^{8}$. A crítica, nesse ponto, é claramente dirigida a Carl Schmitt. O teórico defende que não existe algo como conflitos jurídicos e conflitos políticos. Para ele, todo e qualquer conflito que se apresenta em uma sociedade é, generalizadamente, de caráter político ou econômico, mas isso não impede que seja submetido ao direito. É posição que casa perfeitamente com o aspecto dinâmico da teoria de Kelsen, sobretudo, no que podemos resumir como o "toque de Midas"9 do direito. Para ilustrar a impossibilidade de existir, dentro do direito - e destaca-se o "dentro" -, algo como "não-direito", Kelsen diz que o direito é tal qual o rei Midas. Tudo que este tocava transformava-se em ouro e, do mesmo modo, tudo que aquele toca transforma-se em direito, em jurídico. É fácil, então, relacioná-los. Todo e qualquer conflito pode ser conflito "jurídico" desde que se entenda que o direito deva lidar com ele.

\section{A QUESTÃO DA SOBERANIA}

Há uma terceira objeção que Kelsen enfrenta no livro: a questão da soberania. Aceitando o princípio da soberania como uma das diretrizes de funcionamento do Direito Internacional, poder-se-ia dizer que a ideia de um tribunal compulsório fere a autonomia dos Estados Nacionais e, portanto, sua soberania, conceito central da teoria do Estado, sem o qual um Estado não teria sua razão de ser. Kelsen entende ser tal temor infundado. O tribunal seria compulsório, mas a adesão a ele não, o que não implicaria, de forma alguma, um desrespeito à soberania dos ditos Estados Nacionais. Poder-se-ia dizer ainda que mesmo que fosse o caso, a obrigatoriedade de se fazer valer uma decisão internacional em território nacional fere a

\footnotetext{
${ }^{7}$ KELSEN, Hans. Teoria Pura do Direito. São Paulo: Martins Fontes, 2009, p. 264-265

${ }^{8}$ KELSEN, Hans. A paz pelo Direito. São Paulo: Martins Fontes, 2011, p. 26-27.

${ }^{9}$ KELSEN, Hans. Teoria Pura do Direito, p. 308
} 


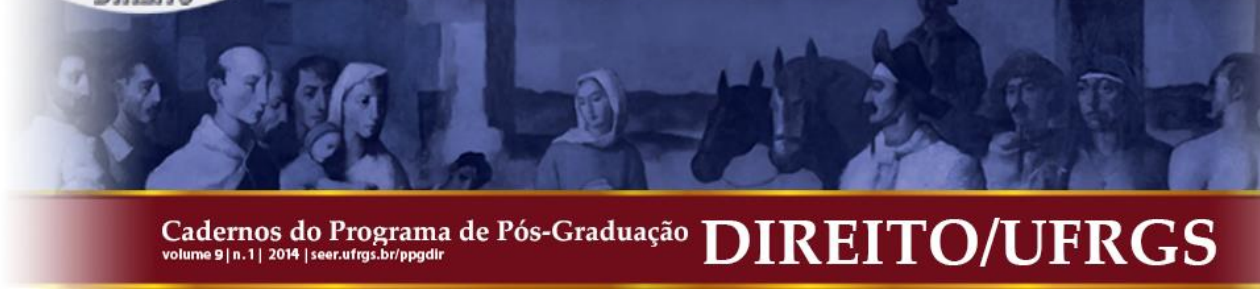

soberania do Estado Nacional. Kelsen diz que se fosse o caso, não seria possível falar de soberania de modo algum, visto que recorrentemente os tribunais nacionais valem-se, às vezes com exigência a procedimentos específicos, às vezes não, do Direito Internacional, aplicandoo, contudo, como "Direito Nacional". Mas ainda que o seja aplicado de tal forma, entende o autor, não deixa de sê-lo Internacional.

O que caracteriza um crime como internacional, diz a doutrina tradicional, é o fato de tal crime ser imputado à "pessoa" do Estado, de modo que tal responsabilização seja "coletiva" e não individual, impossibilitando a ideia de se responsabilizar um indivíduo por crimes internacionais. Kelsen não segue esse raciocínio. Para o teórico vienense, um ato é estatal se a pessoa que o realizou é tida como um órgão competente para realizá-lo, de modo que, um ato tido como punível, como num dos exemplos do livro, uma sabotagem desempenhada por espiões ingleses em um porto americano no qual se detinham navios do Reino Unido, se sustentado pelo respectivo país como um "ato de Estado" passa a ser considerado como delito internacional e, de tal forma, a ser julgado pela Justiça Internacional. O que Kelsen quer dizer é que ainda quando responsabilizamos o Estado pela conduta, estamos, primariamente, responsabilizando alguém por essa conduta, alguém que, particularmente, constitui-se como órgão competente pelo Estado para realizar a conduta tida como indevida.

\section{O PAPEL DOS PRINCÍPIOS}

Kelsen irá adotar uma nova postura com relação ao tema dos princípios, que poderiam servir para suprir a ausência de regras pactuadas entre os Estados. Para sustentar tal opinião, Kelsen recorre ao seu arsenal teórico tradicional, pois, como já apontamos anteriormente, o jurista vienense vê a sentença do juiz como criação normativa. Para La Torre e Garcia Pascual, em ensaio introdutório para a edição espanhola da obra, comentam: "Kelsen critica la solución a tal cuestión basada sobre la idea de que la sentencia del juez sea meramente declarativa de normas preexistentes, sin valor creativo o productivo de derecho". Sendo assim, "El juez produce derecho; pero - atención - lo produce en modo substancialmente diverso del adoptado por el legislador. Tal admisión es una novedad en la 'doctrina pura', a tenor de la cual la única diferencia entre ley y sentencia viene dada por el diverso grado de 


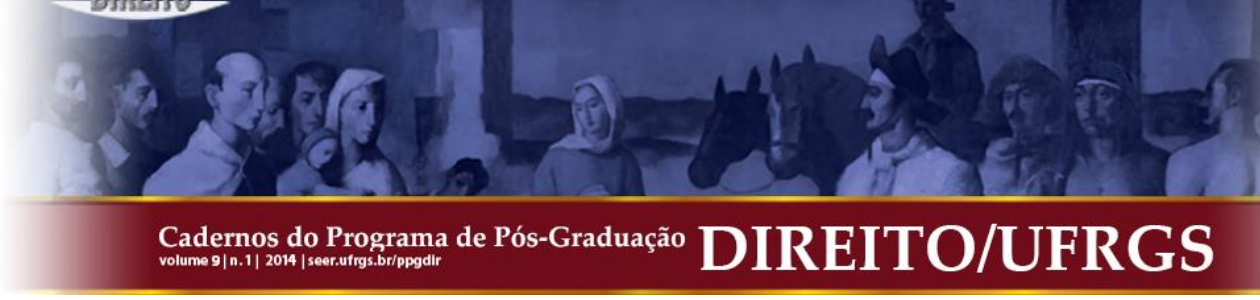

generalidad de los dos tipos de proposición" $"$. No modelo da Teoria Pura do Direito de 1934, o ato do legislador e o ato judiciário distinguem-se somente pelo grau de generalidade o legislativo cria normas gerais e o judiciário, normas particulares (em regra). A administração pública seria equivalente à judicial, uma vez que ambas criam normas particulares. Mas, em Apaz pelo direito, é introduzida uma diferença procedimental: o procedimento judicial distingue-se também pela autonomia conferida ao juiz (e a obrigação de produzir um julgamento imparcial e objetivo).

Nas palavras de Kelsen, "El examen objetivo y la decisión imparcial de la cuestión de si ha sido o no violado el derecho es la etapa más importante, la etapa esencial de todo procedimiento jurídico. Mientras no sea posible privar a los Estados interesados de la prerrogativa e decidir la cuestión del derecho y transferirla de una vez por todas a una autoridad imparcial, a saber, un tribunal internacional, es completamente imposible todo nuevo progreso en el camino de la pacificación del mundo" $"$.

Kelsen vai mais adiante, concluindo que um Tribunal de Direito Internacional possa julgar não sobre normas, mas sim sobre princípios. Kelsen escreveu que "Incluso si la decisión de un Tribunal internacional no constituye la estricta aplicación de una norma jurídica preexistente, se supone que está al menos fundada sobre un principio de derecho.” Sendo assim - decidindo com base em princípios -, o Tribunal internacional não estaria violando o direito nacional dos Estados, uma vez que uma decisão com base nos princípios seria diferente de uma decisão baseada na legislação internacional.

Na opinião de La Torre e Garcia Pascual, "la decisión de los tribunales internacionales es jurídica - concluye Kelsen - en cuanto se supone que está fundada al menos sobre un principio de derecho, esto es, sobre una norma que, aunque todavía no es derecho positivo, debería, según la convicción de jueces independientes, llegar a serlo y que realmente alcanza la categoría de derecho positivo para el caso regulado por la particular decisión judicial"12. Juízes com independência em relação aos Estados nacionais, devemos salientar. Ainda segundo os comentadores mencionados neste parágrafo, a tese de que os juízes decidem não só por meio de normas, mas também por meio de princípios com uma elevada dose de objetividade assemelha-se àquela que seria defendida muitos anos mais tarde por autores como Ronald Dworkin.

\footnotetext{
${ }^{10}$ KELSEN, Hans. La paz por médio del derecho. Madri: Trotta, 2003, p. 17.

${ }^{11}$ KELSEN, Hans. La paz por medio del derecho, p. 47.

12 KELSEN, Hans. La paz por medio del derecho, p. 18.
} 


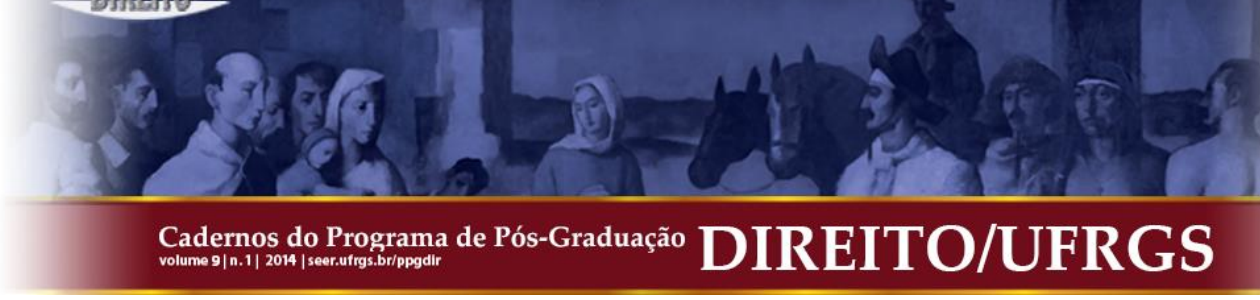

Mas não é possível arrancar mais de Kelsen do que aquilo que ele efetivamente defendeu. Gustavo Zagrebelsky, acertadamente, aponta os limites da concepção kelseniana acerca dos princípios, sublinhando que, de acordo com a teoria do jurista vienense e sua visão gradualista das fontes do direito, corresponde uma teoria da interpretação que vê a aplicação do direito como uma progressão das fontes mais gerais às mais específicas. Sendo assim, a diferença entre princípios (constitucionais) e regras (legislativas) termina por reduzir-se a uma pura questão quantitativa, fazendo com que a novidade dos princípios constitucionais percase. A prova das insuficiências da compreensão de Kelsen acerca dos princípios encontra-se em sua proposta de reduzir ao mínimo os princípios constitucionais a fim de evitar o excesso de discricionariedade do juiz constitucional. O problema é reduzido a uma questão de técnica de redação dos textos constitucionais, quando, na verdade, trata-se de um problema oriundo de profundas transformações determinadas por exigências fundamentais objetivas ${ }^{13}$.

\section{CONSIDERAÇÕES FINAIS}

A paz pelo direito fez parte do "esforço de guerra" particular de Hans Kelsen. Não custa lembrar ao leitor que, naquele momento de sua vida, o autor de Essência e Valor da Democracia, a Teoria Pura do Direito e a Teoria Geral das Normas fazia parte da leva de judeus europeus privados de uma nacionalidade sobre os quais Hannah Arendt refletiu tão bem ao referir-se às condições dos apátridas. Ao aportar em seu último destino como exilado, Kelsen - à época da publicação do livro - já tinha 63 anos, trazendo consigo tão somente uma mala com livros e roupas e nenhuma certeza sobre sua condição material na quadra final de sua vida. No entanto, sua condição de judeu e o fato de ter sido perseguido e ameaçado de morte nos momentos finais de sua estadia na Europa não o levaram a condições desesperadas e ressentidas. Tanto é que o livro A Paz pelo Direito defende que tanto os criminosos de guerra dos vencedores quanto os dos vencidos deveriam enfrentar o julgamento público. Posição que, certamente, desagradava aos comandantes militares do país que lhe concedeu o asilo definitivo.

${ }^{13}$ ZAGREBELSKY, Gustavo. El derecho dúctil. Ley, derechos, justicia. 5ta edición. Madrid: Trotta, 2003, p. 127 (nota 8 ). 
